\title{
Nível de atividade física e satisfação com as aulas de Educação Física: um estudo piloto com estudantes do ensino médio de uma escola pública do interior do Estado do Paraná
}

\section{Physical activity level and satisfaction with Physical Education classes: a pilot study with high school students from a public school in the interior of the state of Paraná}

\author{
Gislaine Cruz Dias \\ Universidade Estadual de Ponta Grossa - UEPG - Ponta Grossa - Brasil \\ gislainecruzdiaass@gmail.com \\ Guilherme Moreira Caetano Pinto \\ Universidade Cesumar - UNICESUMAR - Ponta Grossa - Brasil \\ prof.guilhermecaetano@gmail.com \\ Alfredo Cesar Antunes \\ Universidade Estadual de Ponta Grossa - UEPG - Ponta Grossa - Brasil \\ alfredo.cesar@hotmail.com
}

\begin{abstract}
Resumo
O objetivo do presente estudo foi analisar o nível de atividade física fora da escola e a satisfação com as aulas de educação física de estudantes do ensino médio de uma escola pública localizada em um município do interior do estado do Paraná. A amostra foi de 71 escolares do ensino médio de um colégio da rede estadual de ensino do município de Ponta Grossa. A etapa de coleta de dados ocorreu por meio da aplicação de dois questionários distintos, sendo um sobre atividade física (ATIVIDADES FíSICAS HABITUAIS) e outro sobre a satisfação com as aulas de educação física (Índice de Satisfação em Educação Física - ISEF). A prática de atividade física fora do ambiente escolar ainda não corresponde com as recomendações de 60 minutos por dia de prática de atividade física com intensidade moderada a vigorosa, segundo o Colégio Americano de Medicina Esportiva. Os escolares apresentam-se como "pouco ativos" (33,8\%) e "moderadamente ativos" (32,4\%). A relação estabelecida com a satisfação nas aulas de educação física por meio da expressão de sentimentos positivos tem forte ligação aos níveis de atividade física, diante do expresso como prazer/alegria e motivação $(23,3 \%)$. 0 professor de educação física deve ser o principal fomentador para a adoção de um estilo de vida ativo, utilizando-se de diferentes conteúdos e atividades como ferramentas.
\end{abstract}

Palavras-chave: Atividade Física. Educação Física. Satisfação.

\section{Abstract}

The aim of the present study was to analyze the level of physical activity outside school, and the satisfaction with Physical Education lessons by High School students in a public school located in a small town in the countryside in the State of Paraná. The sample was formed by 71 High School students of a State school in the town of Ponta Grossa. The stage of data collection occurred through the application of two distinct questionnaires, one on physical activities (HABITUAL PHYSICAL ACTIVITIES) and the other on the 
satisfaction with the Physical Education lessons (ISEF - "Brazilian Index of Satisfaction in Physical Education"). The practice of physical activities outside the school environment still does not correspond to the recommendations of 60 minutes a day doing a physical activity with moderate and vigorous intensity, according to the American College of Sports Medicine. The students are considered "a little active" (33,8\%) and "moderately active" $(32,4 \%)$. The relationship established with the satisfaction in the Physical Education lessons through the expression of positive feelings has a strong connection with the levels of physical activity, before what was expressed as pleasure/joy and motivation (23,3\%). The teacher of Physical Education must be the main promoter for the adoption of an active lifestyle, making use of different contents and activities as tools.

Keywords: Physical Activity. Physical Education. Satisfaction.

\section{Introdução}

A Educação Física (EF) é a área que trata a motricidade humana como meio de atingir, melhorar ou manter a saúde física dos indivíduos. Além disso, é fator de extrema importância para qualidade de vida (QV), que envolve fatores pessoais e socioambientais. Desta maneira, não há como falar em EF e não se tratar de atividade física (AF).

A disciplina de EF é respaldada pela lei № 10.793, de 10 de Dezembro de 2003, Artº26 par. $3^{\circ}$ com o seguinte texto: A EF, integrada à proposta pedagógica da escola, é componente curricular obrigatório da educação básica, sendo sua prática facultativa ao aluno: I - que cumpra jornada de trabalho igual ou superior a seis horas; II - maior de trinta anos de idade; III - que estiver prestando serviço militar inicial ou que, em situação similar, estiver obrigado à prática da EF; IV - amparado pelo Decreto-Lei no 1.044, de 21 de outubro de 1969; V - (VETADO); VI - que tenha prole.

$\mathrm{O}$ desenvolvimento da EF enquanto disciplina obrigatória deve alcançar alguns objetivos previstos nos Parâmetros Curriculares Nacionais do Ensino médio (PCN's), um dos documentos que norteia a educação, bem como as Diretrizes Curriculares Nacionais e a Base Nacional Comum Curricular (BNCC) aprovada no dia 04 de dezembro de 2018 (OLIVEIRA; MORENO, 2018). Um dos objetivos destacados pelos PCN's é a adoção de uma postura ativa na prática de atividades físicas e consciente da importância delas na vida do cidadão (BRASIL, 2000, p. 42).

Tais objetivos tornam-se importante tendo em vista que cada vez mais o sedentarismo ganha espaço na vida das pessoas e os problemas de saúde acabam sendo recorrentes. Pimenta (2013) afirma que o desenvolvimento do capitalismo, 0 crescimento demográfico, o desenvolvimento tecnológico, o processo de industrialização, a globalização e o sedentarismo contribuíram para a emergência da obesidade como um problema de saúde pública mundial, constituindo-se em epidemia. Greca et al. (2016) coaduna com o exposto por Pimenta (2013), e complementa que o sedentarismo está ligado aos hábitos de vida desde a infância.

Além do sedentarismo estar relacionado com o aparecimento de doenças hipocinéticas (TEIXEIRA et al., 2016), deve-se considerar que a adoção de um estilo de vida ativo reduz o risco do surgimento de doenças crônicas, além de repercutir positivamente na saúde do indivíduo (GOMES; MINAYO, 2016; PAIVA et al., 2016). Isto evidencia a importância dos objetivos citados pelos PCN's quanto a adoção de hábitos saudáveis.

No entanto, ainda que a adoção do hábito de vida saudável seja um consenso entre os pesquisadores, estudos recentes mostram que a população brasileira ainda apresenta boa parcela de indivíduos com sobrepeso (54\%) e 46\% de indivíduos que adotam um estilo de vida sedentário (VIGITEL, 2017, p. 68). 
Ciente do papel da disciplina de EF na escola previsto nos PCNs, e diante do cenário de sobrepeso e sedentarismo acima exposto, é importante identificar o nível de AF fora da escola e a satisfação com as aulas de EF dos estudantes, fazendo uma analogia com relação ao papel da EF escolar. Logo, a pergunta norteadora desta pesquisa é: Como está o nível de AF fora da escola e a satisfação com as aulas de EF dos estudantes do ensino médio de uma escola pública localizada em um município do interior do estado do Paraná?

Esta pesquisa justifica-se na possibilidade de apresentar a realidade local dos escolares em relação ao nível de AF praticado por eles e após os resultados obtidos, seja possível a realização de futuras intervenções sobre esse aspecto.

Em face ao contexto supracitado, o objetivo geral do presente estudo é analisar o nível de AF fora da escola e a satisfação com as aulas de EF dos estudantes do ensino médio de uma escola pública localizada em um município do interior do estado do Paraná.

\section{Procedimentos metodológicos}

Baseado na literatura de Gil (2002) a presente pesquisa classifica-se como de caráter quantitativo, de natureza aplicada e quanto aos objetivos, como pesquisa exploratória.

O colégio estadual selecionado para a coleta de dados, de acordo com os dados disponíveis no site da Secretaria de Estado de Educação do núcleo regional de Ponta Grossa, conta com 11 turmas de ensino médio e com 360 matrículas. No entanto, a pesquisa fora realizada somente com as turmas do período matutino, sendo três turmas de $1^{\circ}$ anos; duas turmas de $2^{\circ}$ e $3^{\circ}$ anos, totalizando 7 turmas com média aproximada de 28 alunos por turma. Sendo assim, o método para obtenção da população amostral desta pesquisa foi amostragem não probabilística por acessibilidade.

A escolha desse colégio se deu devido à situação problema ter sido identificada neste local, no momento de participação efetiva no Programa Institucional de Bolsas de Iniciação à Docência (PIBID), programa que permite a aproximação do graduando com a realidade das escolas públicas. Além disso, o colégio está situado em uma região central do bairro de Uvaranas e os escolares ali matriculados apresentam classes sociais distintas.

Os instrumentos para a coleta de dados foram dois questionários: "Índice de Satisfação em Educação Física" desenvolvido por Fábio Brandolin, Mariane Campelo Koslinski e Antonio Jorge Gonçalves Soares. Este comtempla 42 questões que buscam evidenciar o nível de satisfação dos escolares com a aula de EF no ensino médio, bem como o perfil sociodemográfico dos alunos, suas habilidades nos esportes, organização da aula de EF e infraestrutura da escola. No entanto, as perguntas iniciais do questionário não fazem referência ao principal objetivo estudado nessa pesquisa, por isso a aplicação se deu a partir da questão 31, as quais objetivam diretamente as aulas de EF.

O segundo questionário, intitulado "Atividades Físicas Habituais" desenvolvido por Russel R. Pate - University of South Carolina/EUA e traduzido e adaptado por Markus Vinícius Nahas - NuPAF/UFSC, 2003, contempla 11 questões sobre as atividades ocupacionais diárias e as atividades de lazer do indivíduo. Quanto mais positiva for a resposta, maior será sua pontuação, seguindo a seguinte classificação: $0-5$ pontos: inativo; $6-11$ pontos: pouco ativo; $12-20$ pontos: moderadamente ativo; 21 ou mais pontos: muito ativo.

A participação na pesquisa foi de caráter voluntário e os participantes deveriam se enquadrar nos seguintes critérios: faixa etária de 15 a 19 anos de idade e de ambos os sexos, visto que são os últimos anos da educação básica em que estarão em contato direto com a disciplina de EF; conformidade com o termo de Assentimento/Consentimento 
Livre e Esclarecido (anexo 1). Aqueles que não estivessem de acordo com esses critérios não poderiam participar da pesquisa.

Em um primeiro momento foram entregues os referidos termos aos escolares para que conseguíssemos a autorização de seus responsáveis (no caso dos menores de idade). Foi entregue um total de 150 termos para os alunos que estavam presentes nesta data, e tivemos o retorno de apenas 75 devidamente preenchidos. Em um segundo momento foram aplicados os instrumentos de coleta em suas respectivas salas de aula, com orientações sobre cada questionário. O tempo de duração da aplicação dos questionários foi em média de 15 minutos, e ao término de seu preenchimento os questionários eram entregues em mãos para o pesquisador.

\section{Resultados e Discussão}

Ao total, obteve-se uma amostra de 74 indivíduos que totalizou 149 questionários respondidos, sendo 75 sobre "Atividades Físicas Habituais" (anexo 2) e 74 sobre "Índice de Satisfação em Educação Física” (anexo 3). No entanto, ao efetuar uma análise, observou-se que vários instrumentos apresentaram preenchimentos incorretos. Acreditase que isso tenha ocorrido por leitura incompleta de enunciados e também por ausência de interpretação de texto. A Tabela 1 , demonstra o número de questionários preenchidos corretamente:

Tabela 1: Número de participantes por questionário.

\begin{tabular}{cccc}
\hline Instrumento de coleta & Meninas & Meninos & TOTAL \\
\hline ISEF & 23 & 17 & 40 \\
ATIVIDADES FISICAS HABITUAIS & 45 & 25 & 70 \\
\hline
\end{tabular}

Fonte: Pesquisa de campo (2018).

Apesar de se tratar de dois questionários diferentes, porém relacionados, os instrumentos foram considerados nesta pesquisa como um elemento só. Desta maneira, nota-se que houve uma defasagem de 34 questionários no preenchimento do ISEF. Em contrapartida, somente 5 sobre AF habituais foram desconsiderados.

Os resultados da presente pesquisa partem da população amostral estudada, que contemplou 70 escolares sendo 45 meninas e 25 meninos. Quanto à faixa etária do grupo estudado, foram obtidas as seguintes informações (Gráfico 1):

Gráfico 1: Idade dos escolares participantes da pesquisa sobre o nível de AF fora da escola e o nível de satisfação com as aulas de EF.

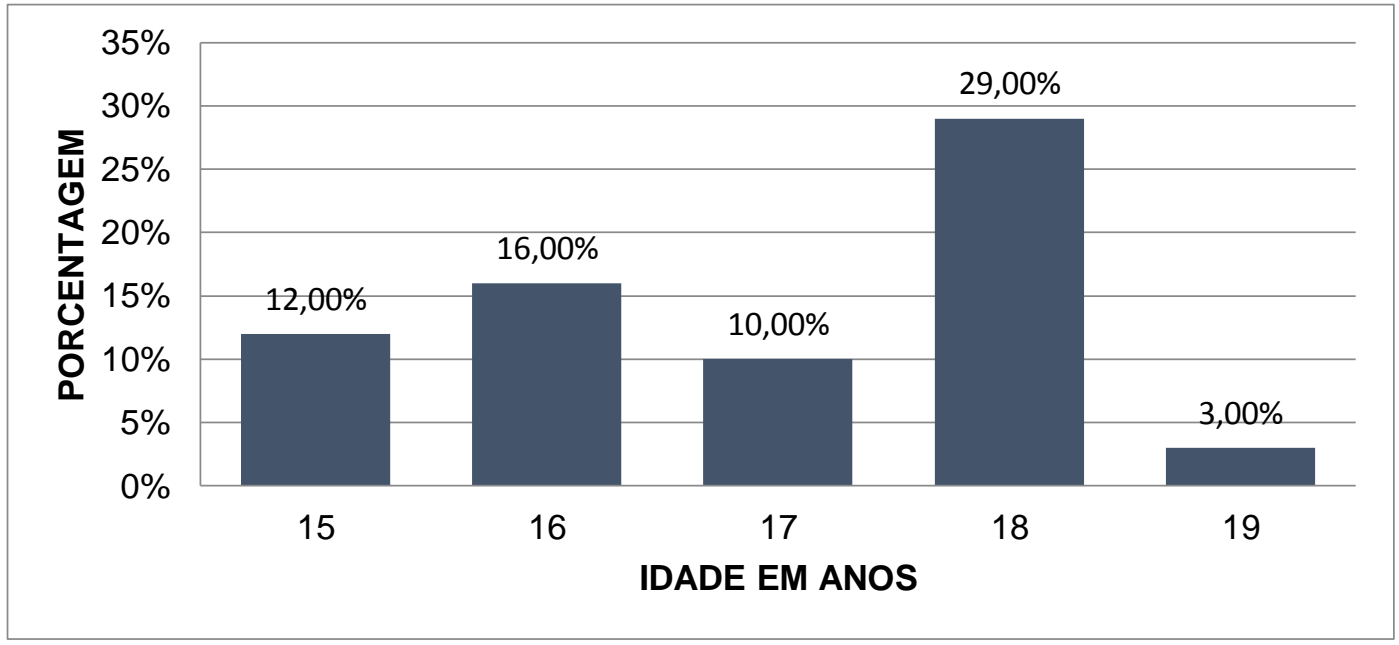

Fonte: Pesquisa de campo (2018). 
Desta população, as seguintes subdivisões e variáveis foram estabelecidas:

Tabela 2: Cor da pele de acordo com a classificação do IBGE (Instituto Brasileiro de Geografia e

\begin{tabular}{cccc}
\multicolumn{4}{c}{ Estatística). } \\
\hline Cor da pele (IBGE) & $\mathbf{1}^{\circ}$ ano & $\mathbf{2}^{\mathbf{0}}$ ano & $\mathbf{3}^{\mathbf{0}}$ ano \\
\hline Branca & 14 & 8 & 15 \\
Parda & 6 & 9 & 9 \\
Amarela & 3 & 3 & 0 \\
Preta & 0 & 3 & 0 \\
Indígena & 0 & 0 & 0 \\
\hline
\end{tabular}

Com base nas tabelas 1 e 2, e no gráfico 1, pode-se fazer algumas considerações sobre o perfil dos alunos que participaram do presente estudo. Nota-se que a maior parcela de estudantes é feminina e da cor branca. O número de estudantes negros é uma minoria em relação ao total de escolares participantes da pesquisa. Além disso, a maior parte da amostra concentra-se na faixa etária de 18 anos, pois são os dois últimos anos do período escolar do ensino médio ( $2^{\circ}$ e $3^{\circ}$ anos). No que se refere ao gênero dos escolares, a maior participação feminina contrapõe os dados do censo escolar que apresentam que a maior parte das matrículas do ensino médio denotou o gênero masculino com 50,3\% e para o gênero oposto 49,7\% (BRASIL, 2015). No entanto pode-se levar em consideração o fato de alguns meninos terem esquecido de retornar o termo de consentimento.

Dado os aspectos relacionados com cada variável estabelecida anteriormente, apresenta-se um levantamento sobre o nível de AF fora da escola para os alunos do ensino médio.

\subsection{Atividades Físicas Habituais}

Exibe-se, na tabela 3, a classificação dos escolares quanto ao seu nível de AF fora do ambiente escolar de acordo com o questionário (Atividades Físicas Habituais) adaptado por Nahas (2006).

Tabela 3: Nível de AF de acordo com as séries.

\begin{tabular}{|c|c|c|c|c|}
\hline Classificação & 0 - 5: inativo & $\begin{array}{c}6 \text { - 11: pouco } \\
\text { ativo }\end{array}$ & $\begin{array}{c}12 \text { - 20: } \\
\text { moderadamente } \\
\text { ativo }\end{array}$ & $\begin{array}{l}21 \text { ou mais: } \\
\text { muito ativo }\end{array}$ \\
\hline 1ano & 3 & 4 & 12 & 4 \\
\hline $2^{\circ}$ ano & 6 & 10 & 2 & 5 \\
\hline 3 ano & 4 & 10 & 9 & 2 \\
\hline Total & 13 & 24 & 23 & 11 \\
\hline
\end{tabular}

Fonte: Pesquisa de campo (2018).

A classificação do nível de AF dos escolares com relação às suas respectivas séries demonstrou que ouve uma equivalência entre as turmas, pois os valores não tiveram distanciamentos. Pode-se dizer que os escolares do $2^{\circ}$ e $3^{\circ}$ anos são categorizados como "pouco ativos", enquanto os alunos do $1^{\circ}$ ano são "moderadamente ativos". Vale lembrar que os estudantes do $1^{\circ}$ ano concentram-se nas faixas etárias de $15 / 16$ anos.

A Tabela 4, apresenta os resultados quanto ao nível de AF dos alunos quanto ao gênero dos escolares. 
Tabela 4: Nível de AF de acordo com o gênero dos escolares.

\begin{tabular}{|c|c|c|c|c|}
\hline Classificação & 0 - 5: inativo & $\begin{array}{c}6-11: \text { pouco } \\
\text { ativo }\end{array}$ & $\begin{array}{c}12-20: \\
\text { moderadamente } \\
\text { ativo }\end{array}$ & $\begin{array}{l}21 \text { ou mais: } \\
\text { muito ativo }\end{array}$ \\
\hline Masculino & 4 & 4 & 10 & 8 \\
\hline Feminino & 9 & 20 & 13 & 3 \\
\hline Total & 13 & 24 & 23 & 11 \\
\hline
\end{tabular}

Fonte: Pesquisa de Campo (2018).

Para melhor visualização dos resultados comparados com o gênero dos escolares, o Gráfico 2, ilustra as mesmas informações da Tabela 4.

Gráfico 2: Nível de AF de acordo com o gênero dos escolares.

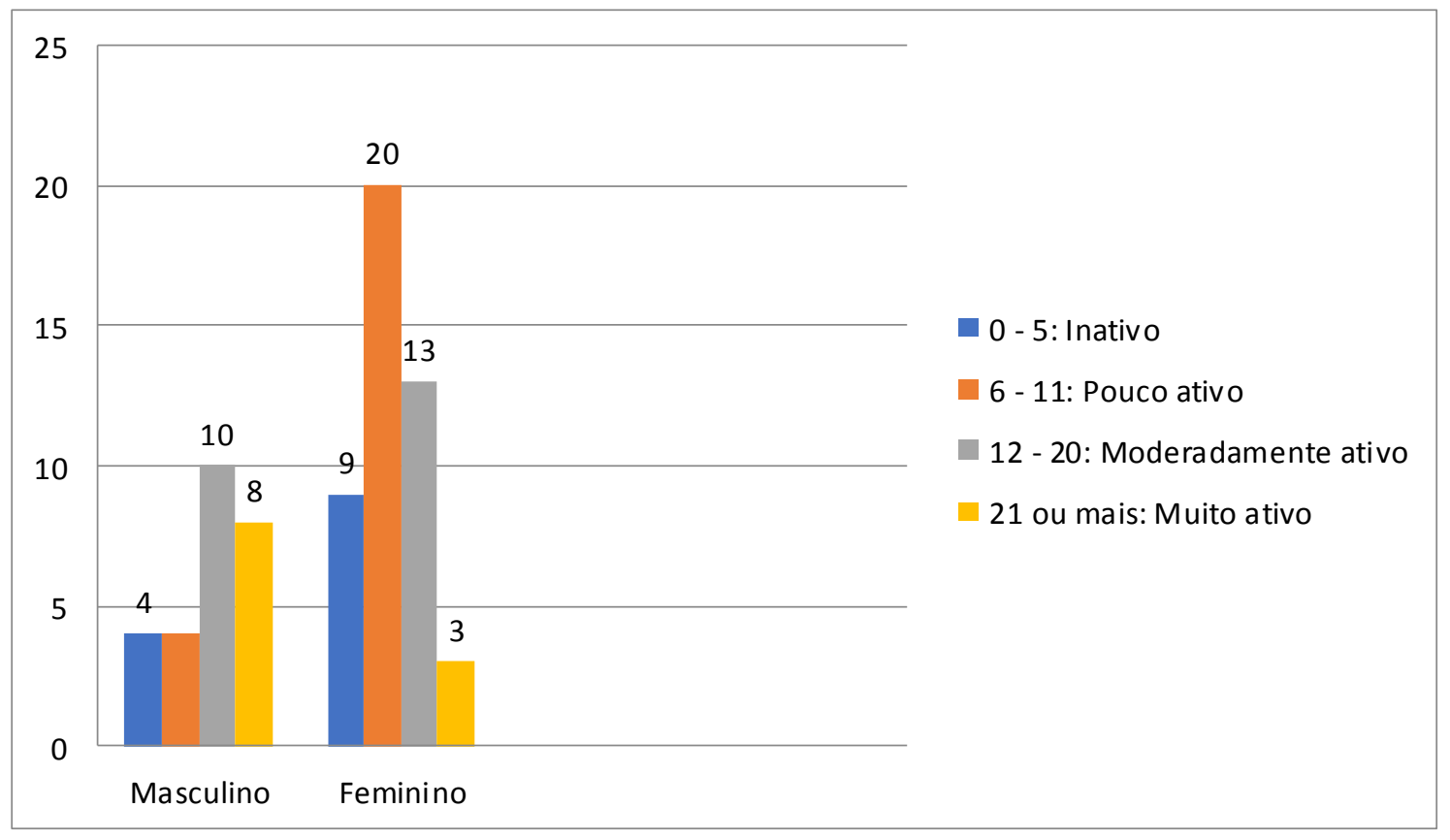

Fonte: Pesquisa de campo (2018).

Pode-se notar que as meninas, que representam a maior parcela da amostra, apresentam um nível de AF inferior em relação aos meninos, visto que seus valores para classificações como "muito ativo" e "moderadamente ativo" ficaram próximos aos valores dos meninos que compunham um número menor na amostragem.

De acordo com as informações contidas nas tabelas 3, 4 e Gráfico 2, percebe-se que o gênero masculino é mais ativo fisicamente. Isto não é nada novo para a literatura, pois várias pesquisas que buscam avaliar o nível de AF dos escolares identificam as mesmas características. Os fatores que justificam esse cenário são a menor participação das meninas nas aulas de EF, como identificado na pesquisa de Bacil et al. (2013). Neste observou-se que apenas 78,9\% das alunas participam das aulas de EF. Além disso, o maior envolvimento masculino em AF pode também ser justificado pela construção social de papéis destinados para homem e mulher na sociedade. De acordo com Guedes et al. (2001):

Essa situação implica que moças e rapazes devem ser direcionados a assumir diferentes funções e, desde muito jovens, a participação dos rapazes em atividades esportivas e em esforços físicos mais intensos é valorizada mais 
positivamente que a das moças. Ainda, na adolescência, por conta de valores sociais deturpados, algumas moças podem adotar postura de que a prática de exercícios físicos e de esportes é proibitiva à sua condição de mulher. Esse estereótipo social, claramente identificado na sociedade atual, vem apresentando enorme resistência a mudanças.

O Gráfico 3, mostra os resultados obtidos na classificação geral dos indivíduos.

Gráfico 3: Nível de AF fora da escola em alunos do ensino médio.

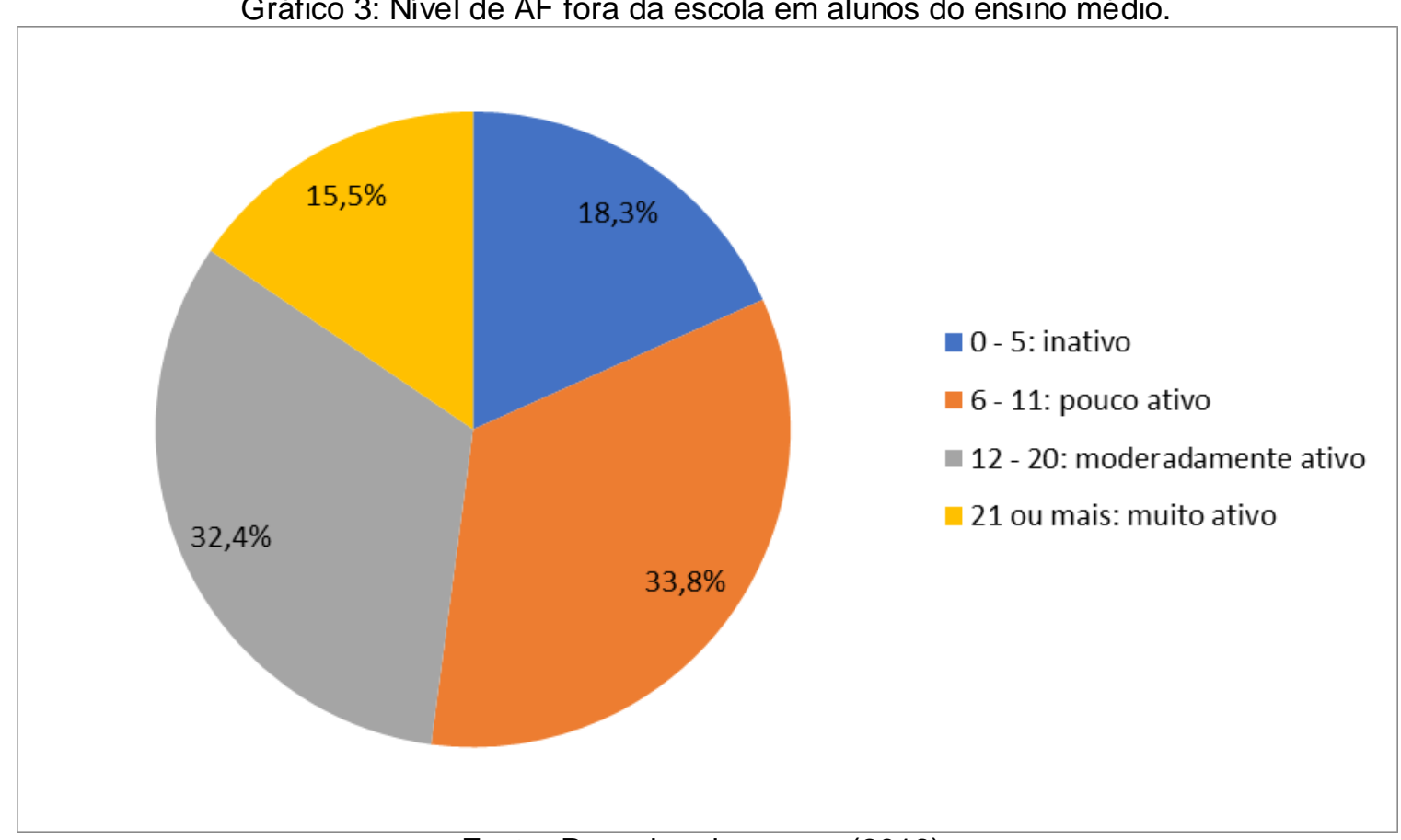

Fonte: Pesquisa de campo (2018).

Da população amostral estudada em uma extremidade estão os que são inativos, $18,3 \%$. No outro polo estão os que são muito ativos, somando $15,5 \%$. Houve uma aproximação de valores para os que são pouco ativos $(33,8 \%)$ e os que são moderadamente ativos $(32,4 \%)$. Para a atual situação da população brasileira isto não é novidade, pois corrobora com as pesquisas realizadas pela VIGITEL (Vigilância de fatores de riscos e proteção para doenças crônicas por inquérito telefônico) que apontam que $54 \%$ dessa população tem sobrepeso e (VIGITEL, 2018, p.103), e 46\% não atingem os níveis recomendados para prática de AF é de (VIGITEL, 2018, p. 68).

Este cenário serve como instrumento para que se repense a promoção da saúde. De acordo com Silveira e Silva (2011, p. 465) em seu trabalho sobre os conhecimentos dos escolares sobre AF:

Embora a grande maioria dos adolescentes brasileiros frequente a escola e tenha aulas regulares de $E F$, este espaço didático-pedagógico ainda não Ihes dá oportunidade de compreender os fundamentos das práticas corporais, o que poderia supri-los de conhecimentos necessários para que pudessem manter uma frequência de atividades físicas visando a manutenção e melhoria de sua saúde.

Sendo assim, somente com as aulas de EF da forma como está dividida atualmente, com número de aulas escasso, fica difícil atingir os níveis recomendados para a prática da AF somente dentro do âmbito escolar.

\subsection{ISEF}

Nesta pesquisa buscou-se extrair dos alunos, por meio de ação dedutiva das questões do questionário, identificar quão satisfeitos eram os alunos com as aulas de EF. 
Houve ainda a tentativa de perceber qual era a qualidade das aulas. Para conseguir detectar a satisfação dos escolares, a análise é realizada de acordo com aspectos positivos e negativos referentes às aulas. Se a maior parcela das respostas apresenta caráter positivo, maior o grau de satisfação.

Cabe ressaltar que a questão 37 do ISEF não foi respondida pelos alunos, pois o colégio possui quadra esportiva. A questão 42 ficou restrita aos alunos que trabalham. As perguntas completas estão no anexo 3.

O conceito de satisfação é visto de diferentes formas pela literatura. Satisfação pode ser entendida como um estado psicológico resultante de um conjunto de experiências afetivas as quais se movem entre os polos positivo e negativo, na medida em que o objeto da atividade responde às suas necessidades e corresponde aos seus motivos e interesses (LOPÉZ, 2001, p. 2).

Tendo em vista o conceito supracitado, a primeira questão do questionário em sua versão adaptada referia-se aos sentimentos que os alunos tinham durante as aulas. Cada indivíduo poderia escolher três principais sentimentos, deste modo a frequência de sentimentos experimentados estão expostos no Gráfico 4.

Gráfico 4: Qual sentimento você tem quando participa das aulas de EF?

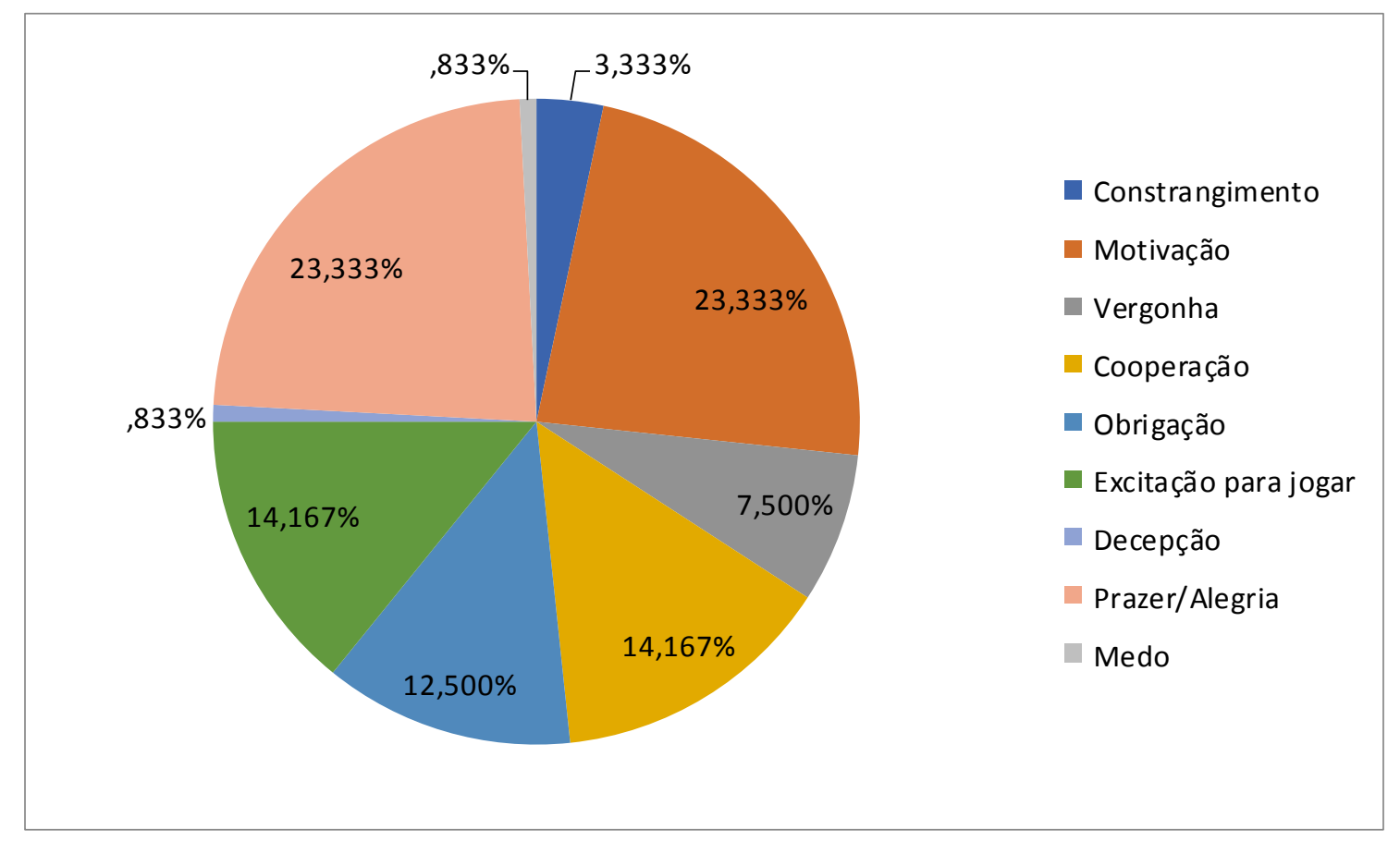

Fonte: Pesquisa de campo (2018).

Os principais sentimentos apontados pelos escolares foram: Prazer/alegria e motivação (23,3\%) e excitação para jogar e cooperação $(14,2 \%)$. Os sentimentos de caráter positivo sobressaíram aos negativos, provando que a maioria dos escolares está satisfeita com as aulas de EF.

No entanto, sabe-se que os sentimentos positivos, como os citados anteriormente, não surgem isoladamente, pois necessitam do estabelecimento de relações interpessoais e a construção de um ambiente harmonioso para que isso ocorra. Para Fonseca (2016, p. 369) as emoções estão mesmo intrinsecamente envolvidas nas funções de atenção, de significação e de relevância e valor social, relacional e motivacional que atravessam as várias fases do processo de aprendizagem, dado que este não se opera de forma isolada ou espontânea, mas sim de forma compartilhada e continuada [...].

A segunda questão do questionário diz respeito ao que os alunos mais gostavam nas aulas. Nesta questão deveria ser marcada apenas uma alternativa. 
Gráfico 5: O que você mais gosta nas aulas de EF da sua escola?

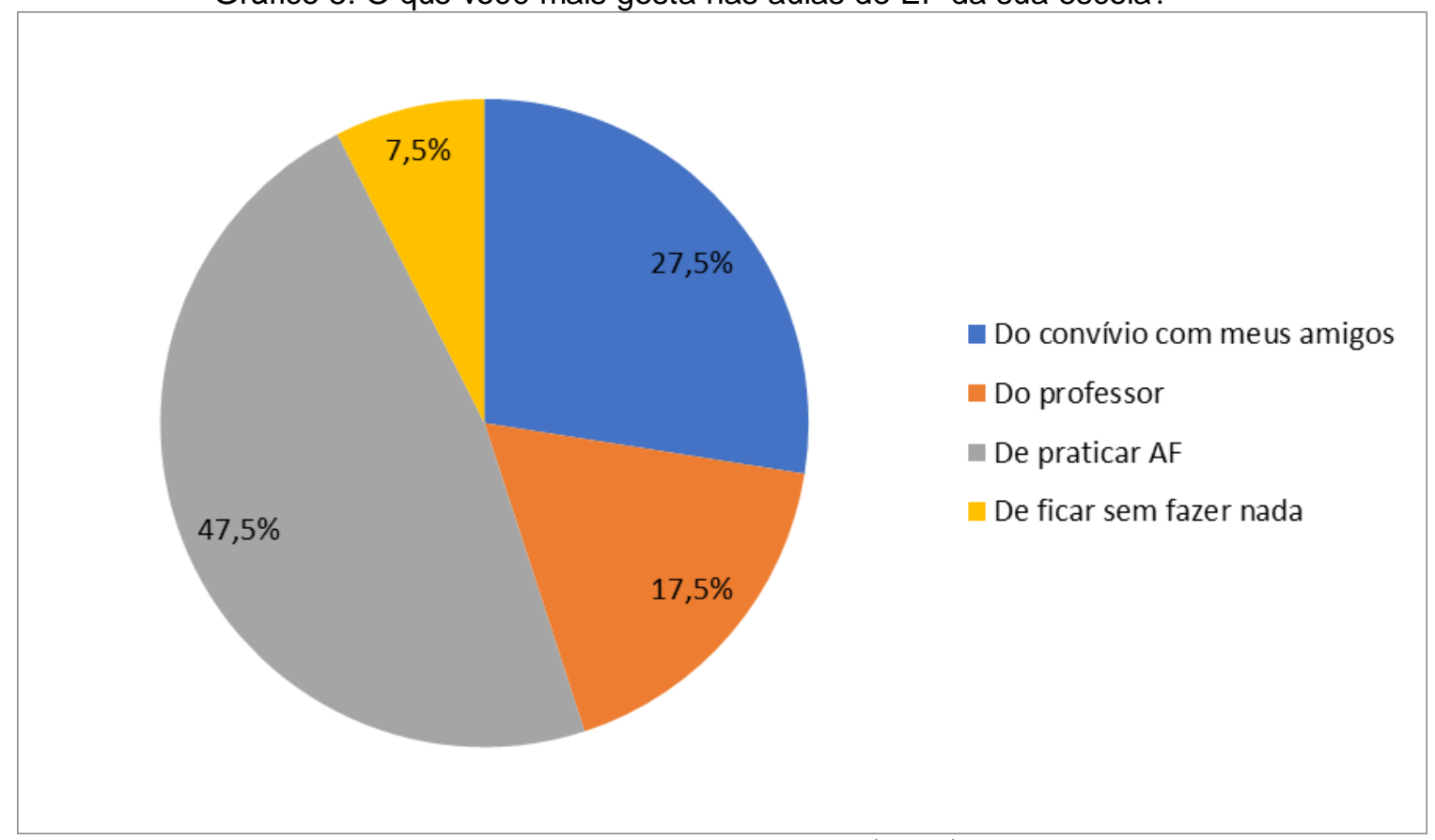

Fonte: Pesquisa de campo (2018).

Nesse aspecto o gosto pela prática de AF ganhou ênfase com $47,5 \%$ das respostas. Isso demonstra a relação da questão com o nível de AF exposto pelo questionário anterior, uma vez que mesmo tendo gosto pela prática de AF os níveis apresentados são baixos. Desta maneira nota-se uma postura contraditória na postura dos escolares, pois subentende-se que por gostarem da prática da AF, logo deveriam apresentar níveis de AF mais altos do que os apresentados anteriormente. Em seguida, o gosto pelo convívio com os colegas de classe $(27,5 \%)$ demonstra que a aula de EF e a prática de AF são fatores integrativos e socializantes.

Guimarães et al. (2001) aponta que a escola é uma das instituições que promove a socialização dos indivíduos, pois é formalizada a partir de regras e normas estabelecidas, e devem propiciar aos alunos a oportunidade de questionar e introjetar o existente. Além disso, de acordo com os PCN's do ensino médio:

\begin{abstract}
A importância do trabalho em grupo está em valorizar a interação aluno - aluno e professor - aluno como fonte de desenvolvimento social, pessoal e intelectual. Situações de grupo exigem dos alunos a consideração das diferenças individuais, respeito a si e aos outros. Trazer contribuições para o cumprimento das regras estabelecidas são atitudes que propiciam o a realização de tarefas conjuntas (BRASIL, 2000, P. 40).
\end{abstract}

Os apontamentos feitos nessa questão contribuem para o surgimento dos sentimentos mencionados na questão anterior. Pode-se dizer que quanto melhor forem as experiências vivenciadas nas aulas de EF, há maior chances de envolvimento dos escolares com a prática de AF.

Para Sanches (2014) quando se pensa em motivação na escola, deve-se considerar o ambiente escolar, as tarefas e atividades proporcionadas na escola, métodos de ensino e avaliação, dentre outras. O professor de EF também faz parte desse ambiente, e deve conhecer e interpretar as emoções de seus alunos, além de estimulá-los a desenvolver o aprendizado a partir de tarefas adequadas, encorajando-os a participar de práticas de esportes, de jogos, de danças, de maneira que também pratiquem essas atividades fora do espaço da escola. 
A terceira questão se referia aos conteúdos trabalhados nas aulas. Os alunos poderiam marcar mais de uma alternativa.

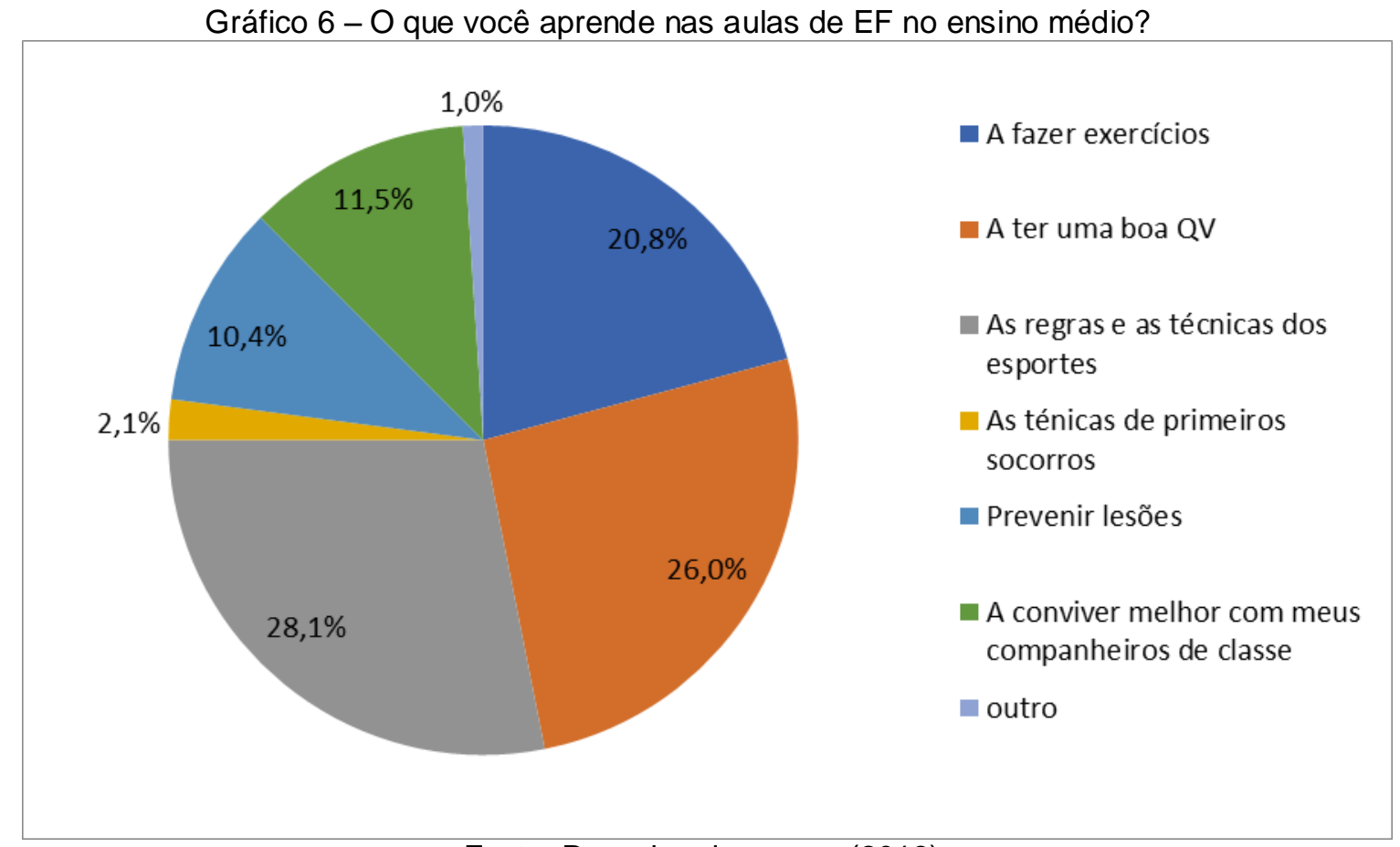

Fonte: Pesquisa de campo (2018).

Os principais aspectos dos conteúdos trabalhados apontados são: as regras e as técnicas dos esportes (28,1\%), acompanhado de informações sobre ter uma boa QV (26\%). Percebe-se uma disparidade com a questão anterior, logo que foi apontado que o convívio com os colegas de classe era de grande interesse, e nesta questão esse mesmo ponto aparece com apenas 11,5\% das respostas. Entende-se, neste sentido, que esse não seja o foco da disciplina e que, portanto, parte de interesse intrínseco dos alunos.

Outro ponto interessante é que o tema prevenção de lesões é pouco explorado (10,4\%), mesmo estando previsto como conteúdo nas Diretrizes Curriculares da Educação básica (DCE, 2008, p. 56), sendo um fator que interfere diretamente a QV (que foi o item mais pontuado na questão), pois uma pessoa lesionada apresentaria uma menor QV, em tese a sensação de bem - estar, principalmente físico apresentaria defasagens.

Segundo Bassani e Richter (2017, p. 7) para aquelas pessoas que praticam AF e esportivas para fins recreativos ou no âmbito do lazer, as lesões podem resultar em dificuldades para cumprir atividades corriqueiras ou mesmo laborais, afastamento provisório ou prolongado das atividades físicas de sua preferência, provocando alterações, às vezes significativas, no seu dia a dia. Neste sentido, fala-se de QV, mas talvez não se englobe todos os seus fatores associados.

Fazendo uma conexão entre a abordagem da saúde renovada e os dados dessa questão, é perceptível que o caráter esportivo é inerente à EF, e esta abordagem faz uma crítica a esse aspecto logo que apresenta um caráter não excludente e busca não fazer uso exclusivo e excessivo de modalidades esportivas.

Ainda no sentido dos conteúdos trabalhados nas aulas, a quarta questão buscouse identificar a percepção dos escolares quanto à serventia dos conhecimentos adquiridos ao longo de sua vida. 
Gráfico 7: Para que Ihe servirá os conhecimentos adquiridos nas aulas de EF no ensino médio ao longo de sua vida?

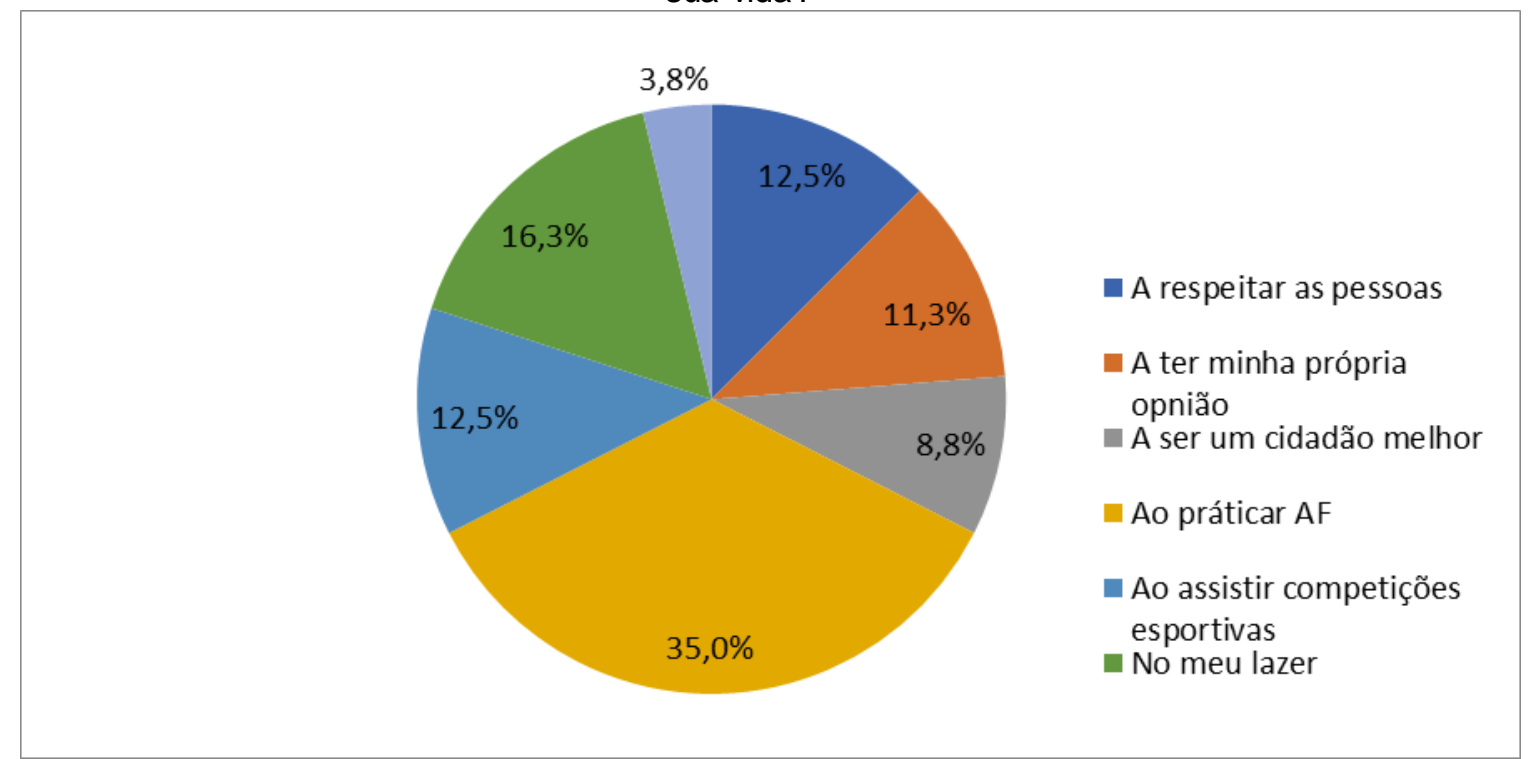

Fonte: Pesquisa de campo (2018).

Ao praticar AF foi o principal motivo (35\%) seguido de auxílio nas atividades de lazer (16,3\%). O aspecto "outro" (3,8\%) faziam apontamentos para uma melhora na QV, atualização de conhecimentos e também para a escolha da profissão dentro desta área de conhecimento (EF). Mesmo a QV sendo um conteúdo trabalhado nas aulas de EF, como mostra a questão anterior, neste momento esse aspecto não se mostra evidente quando se pergunta se isso lhe servirá futuramente.

No entanto os principais pontos dessa questão convergem com um dos objetivos esperados pela abordagem da saúde renovada, o de informar sobre a prática de AF. Acredita-se que há uma falha na questão de conscientização, pois em nenhum momento houve menção sobre a importância e os benefícios que isso pode acarretar sobre problemas como sedentarismo e sobrepeso.

Nahas (2006, p. 134) aponta alguns benefícios da prática da AF como redução da morte prematura por todas as doenças, redução do risco de desenvolver diabetes e hipertensão, redução da sensação de depressão e ansiedade, controle do peso corporal, promoção do bem-estar psicológico e autoestima, entre outros. Nenhum destes fatores foram levantados como conteúdos relevantes a serem levados para a vida dos indivíduos.

Isto deixa a sensação de que a EF na escola não está conseguindo transmitir os benefícios da prática de AF aos alunos. De acordo com Silveira e Silva (2011, p. 465) programas de educação para a saúde devem ser desenvolvidos com o intuito de informar os jovens sobre a influência dos comportamentos de risco, na tentativa de minimizar 0 sedentarismo e, possivelmente, o número de pessoas obesas na adolescência e na vida adulta.

Além dessas questões, a quinta pergunta viria para completar esse ponto. Tratase da expectativa dos escolares com o que deveria ser trabalhado nas aulas. 
Gráfico 8: Em sua opinião, o que a EF no ensino médio deveria oferecer?

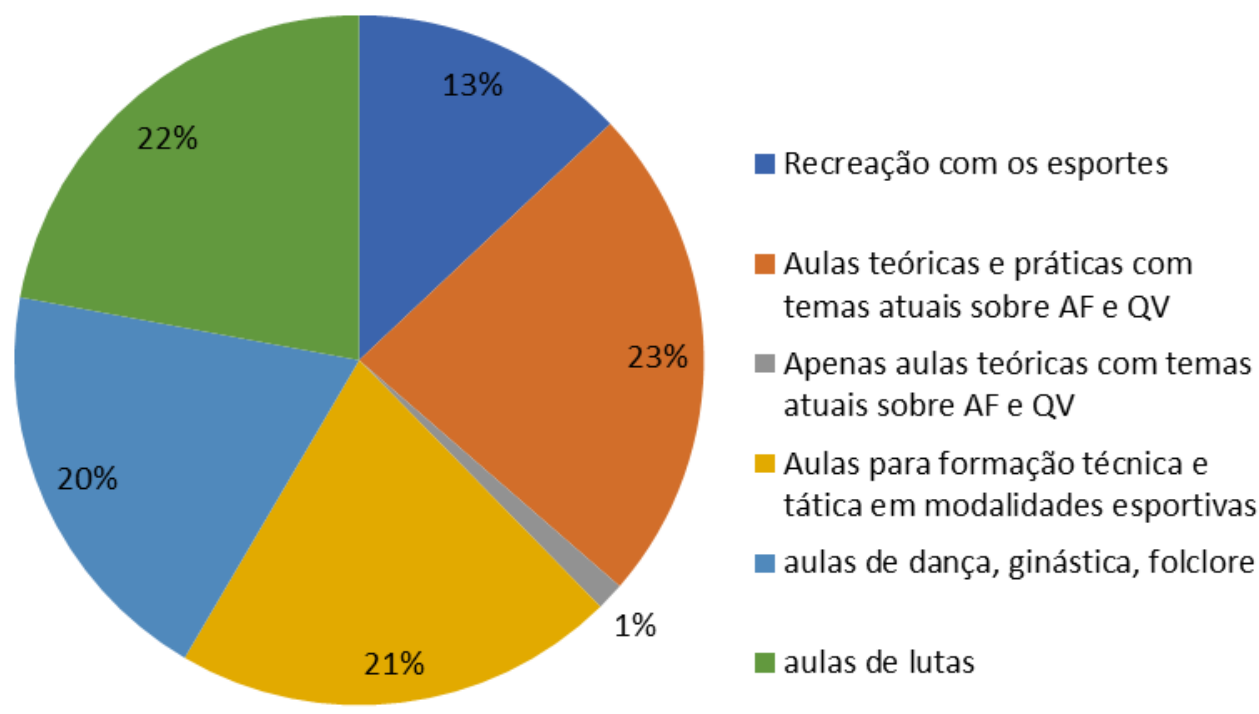

Fonte: Pesquisa de campo (2018).

Ao comparar as questões relacionadas ao que os alunos aprendem com que eles esperariam aprender nas aulas de EF, nota-se a repetição de alguns deles. Aulas teóricas e práticas com temas atuais sobre AF e QV (23\%), aulas de lutas (22\%), aulas para formação técnica e tática (21\%) e aulas de dança, ginástica e folclore (20\%). Percebe-se uma divergência nas respostas, pois quando se tratou do que era aprendido durante as aulas, um dos temas foi a QV e agora essa mesma temática aparece como tema esperado para as aulas de EF.

Neste sentido cabe uma pergunta que fica para ser respondida, qual é o entendimento que os escolares têm sobre QV? Uma hipótese que pode se levantar sobre isso é que o conceito atribuído por eles seja apenas relacionado à prática de AF. Além disso, o que se destaca nessa questão é o apontamento para dois conteúdos que realmente são pouco trabalhados nas aulas de EF, justamente pelo caráter dos esportes tradicionais (handebol, futebol, basquetebol e voleibol) tomarem maior espaço.

A dança e as lutas por muitas vezes não são trabalhadas no decorrer do ano letivo, mesmo sendo dois conteúdos estruturantes previstos nas Diretrizes Curriculares da Educação Básica (DCE). Para o campo das lutas, devem fazer parte do contexto escolar, pois se constituem das mais variadas formas de conhecimento da cultura humana, historicamente produzidas e repletas de simbologias. Ao abordar esse conteúdo, deve-se valorizar conhecimentos que permitam identificar valores culturais, conforme o tempo e o lugar onde as lutas foram ou são praticadas (DCE, 2008, p. 68).

Desenvolver o conteúdo da dança é importante que o professor reconheça que a dança se constitui como elemento significativo da disciplina de EF no espaço escolar, pois contribui para desenvolver a criatividade, a sensibilidade, a expressão corporal, a cooperação, entre outros aspectos (DCE, 2008, p. 72). Nessa perspectiva, identificar as expectativas dos seus alunos é de suma importância para construção de um plano de ensino com significâncias para os mesmos, sem deixar de oferecer tudo àquilo que eles têm direito.

A pergunta seguinte referia-se ao interesse dos escolares em frequentar o ensino médio. Das alternativas disponíveis poder-se-ia assinalar somente uma. 
Gráfico 9: Qual seu principal interesse em frequentar o ensino médio?

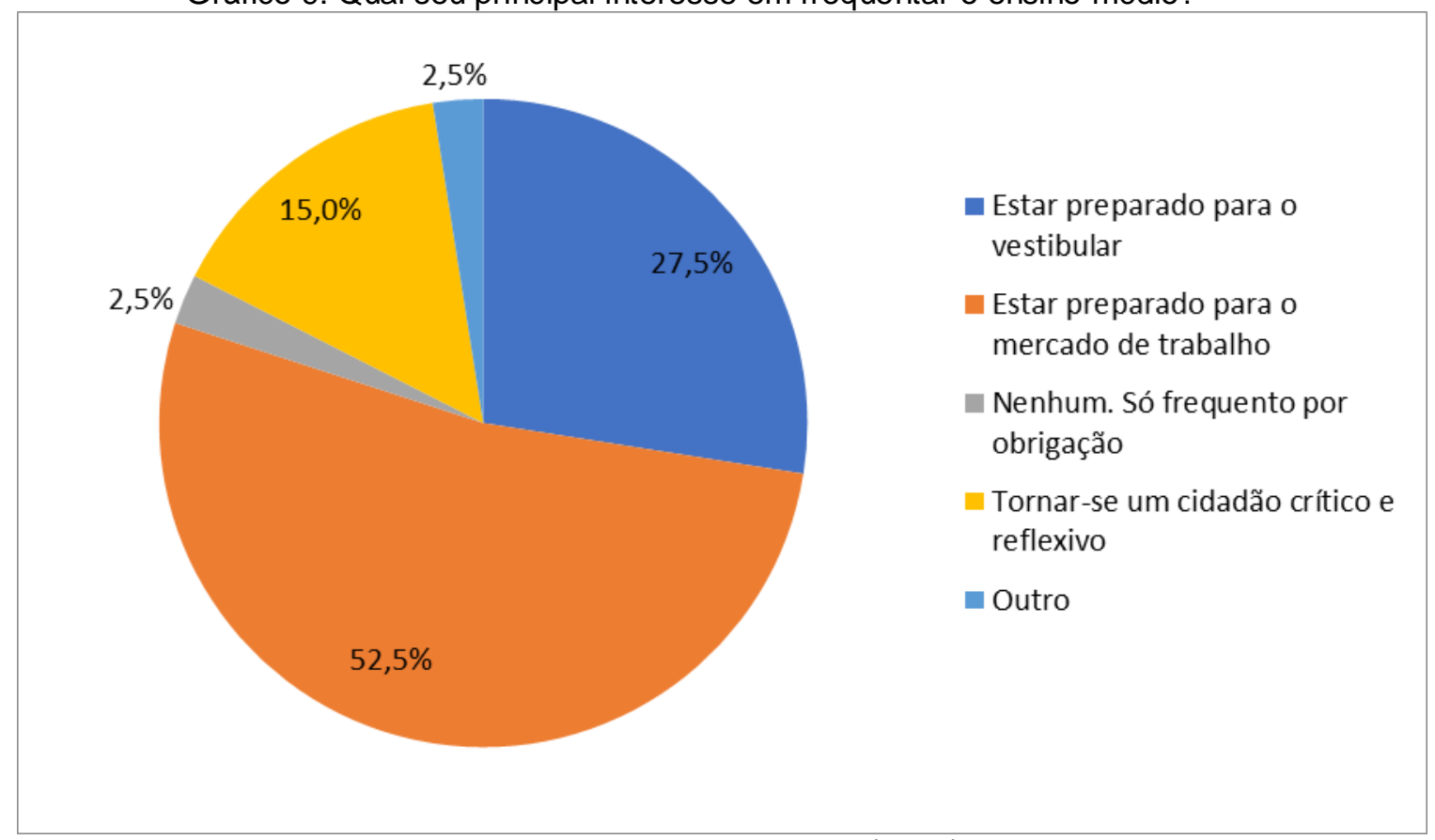

Fonte: Pesquisa de campo (2018).

Para esta questão em específico, não é novidade que a intenção em ingressar no mercado de trabalho seja a mais latente $(52,5 \%)$ e em seguida o interesse pelo curso superior $(27,5 \%)$. Mediante as últimas discussões sobre a reformulação do ensino médio por meio de medida provisória 746/16 e então vigente como lei no 13.415 de 16 de fevereiro de 2017 que alterou a LDB, estabelece como principal modificação a flexibilização dos currículos dando maior autonomia aos escolares, por meio da inserção de itinerários formativos:

O currículo do ensino médio será composto pela Base Nacional Comum Curricular e por itinerários formativos, que deverão ser organizados por meio da oferta de diferentes arranjos curriculares, conforme a relevância para o contexto local e a possibilidade dos sistemas de ensino, a saber: I - linguagens e suas tecnologias; II - matemática e suas tecnologias; III - ciências da natureza e suas tecnologias; IV - ciências humanas e sociais aplicadas; V - formação técnica e profissional. (BRASIL, 2017)

De acordo com a proposta da Base Nacional Comum Curricular (BNCC), essa nova estrutura valoriza o protagonismo juvenil, uma vez que prevê a oferta de variados itinerários formativos para atender à multiplicidade de interesses dos estudantes: o aprofundamento acadêmico e a formação técnica profissional. Além disso, ratifica a organização do Ensino Médio por áreas do conhecimento, sem referência direta a todos os componentes que tradicionalmente compõem o currículo dessa etapa (BRASIL, 2017, p. 467).

A partir disso, acredita-se que futuramente essas perspectivas e interesses dos escolares quanto a sua vida pós-ensino médio fiquem mais claras, não gerando tanta indecisão como é comumente explorado no senso comum.

No que se refere à infraestrutura do colégio para as aulas de EF foram abordadas em duas questões, sendo uma delas sobre a quadra poliesportiva do colégio. 
Gráfico 10: De acordo com a quadra de esportes ou local destinado a prática de EF na sua escola, como você avalia este espaço?

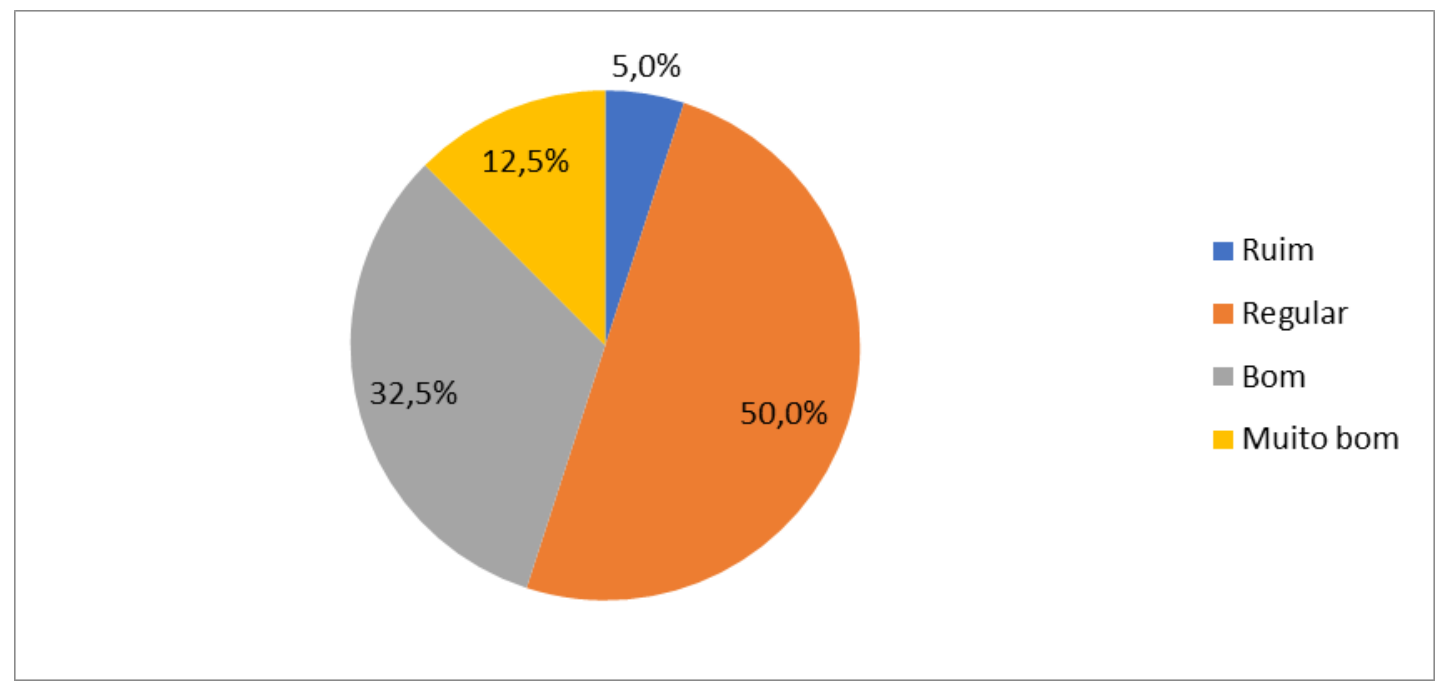

Fonte: Pesquisa de campo (2018).

Metade dos alunos avaliaram a quadra de esportes como regular (50\%) e $32,5 \%$ como "bom". Não é novidade que a realidade da escola pública não é um sonho de consumo e que por muitas vezes as estruturas podem se apresentar precárias, e isso pode afetar o trabalho pedagógico do professor, seja ele de qualquer disciplina.

Quadro 1:Lista de materiais disponíveis para as aulas de EF.

\begin{tabular}{|c|c|c|}
\hline Bolas de basquete & Dama & Raquetes \\
\hline Corda & Bolas de vôlei & Rede de vôlei \\
\hline Tabela de basquete & Mesa de ping-pong & \\
\hline Bolas de futebol & Xadrez & \\
\hline Colchonete & Outros tipos de bolas & \\
\hline
\end{tabular}

Fonte: Pesquisa de campo (2018).

No que diz respeito à estrutura para as aulas de EF (Gráfico 9 e Quadro 1) não há nenhuma surpresa, visto que os materiais mais comuns estão disponíveis para as aulas de EF. Ao comparar o que foi apontado com relação aos conteúdos em relação aos materiais disponíveis, é possível compreender a dificuldade em se trabalhar com novas modalidades e conteúdos com a escassez de materiais diversificados, ou seja, que fuja do convencional.

Silva et al. (2018) realizou uma pesquisa na cidade de Curitiba - PR com 114 escolas da rede pública e privada de ensino, para analisar as estruturas para a prática da AF nas escolas e identificou que a maioria dos espaços em escolas públicas eram considerados como ruins e regulares, enquanto que a rede privada apresentava classificações como excelente.

Mendonça et al. (2018, p. 2449) em sua pesquisa sobre a descrição da prática de AF em adolescentes de João Pessoa - PB, faz uma consideração sobre o que poderiam fazer para aumentar os níveis de AF:

Ações que incentivem e deem suporte a prática de esportes (por exemplo, a criação de programas comunitários voltados a essas práticas, promoção de competições esportivas no tempo lazer), fortalecimento das aulas de EF escolar no ensino básico (melhora na infraestrutura física dos locais de aula, seriação de conteúdos, sistematização curricular, otimização da formação profissional) e maior diversificação das modalidades esportivas ofertadas como conteúdos nessa disciplina (MENDONÇA et al. 2018, p. 2449). 
Com o intuito de identificar quais as práticas esportivas fora do âmbito escolar, e como complemento para o questionário anterior, os escolares deveriam assinalar as atividades que realizavam.

Gráfico 11: Pratica algum esporte ou alguma AF fora da escola?

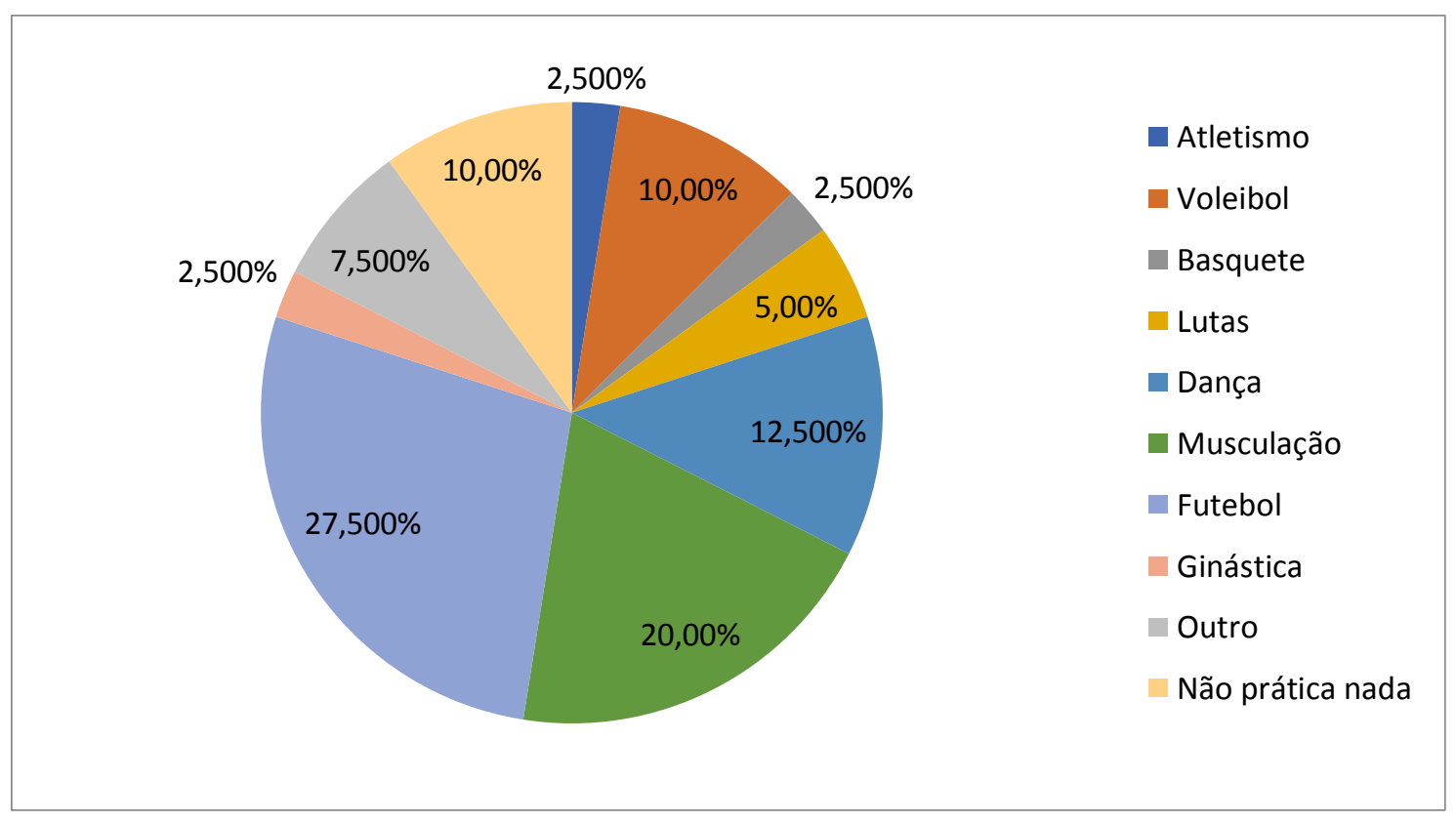

Fonte: Pesquisa de campo (2018).

O futebol $(30,6 \%)$ foi esporte mais assinalado como prática externa, até mesmo pelo grau de popularidade. Em seguida musculação $(22,2 \%)$ e dança $(13,9 \%)$, ambos atividade de fácil disponibilidade em academias. No quesito "outros" $(8,3 \%)$ foram apontadas modalidades como ciclismo, crossfit e caminhada. Mediante o exposto, Nahas aponta:

Os currículos devem enfatizar os objetivos centrais da EF: o desenvolvimento de habilidades motoras e a promoção de $\mathrm{AF}$ relacionadas à saúde. Para atingir esses e outros objetivos da EF, os alunos precisam ser fisicamente ativos, na escola e fora dela (NAHAS, 2006, p. 153).

As respostas para as questões relacionadas a estudo e trabalho estão representadas de maneira única no Gráfico abaixo.

Gráfico 12: Caso você trabalhe, indique o principal motivo.

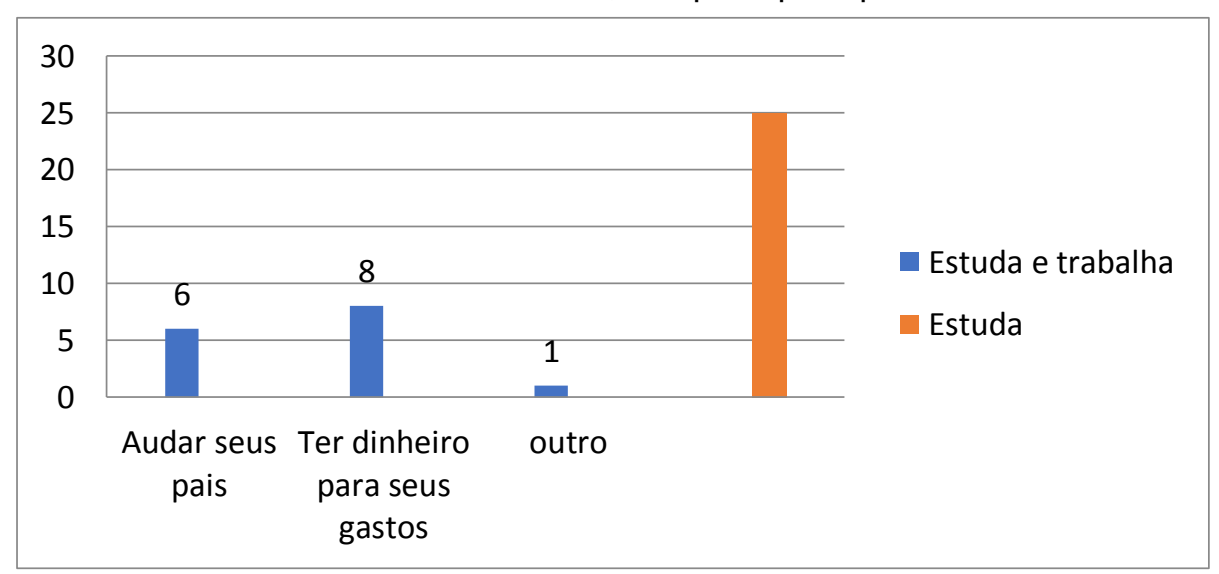

Fonte: Pesquisa de campo (2018). 
Os escolares que apenas estudam correspondem a um grupo de 25 pessoas, enquanto que o número para quem estuda e trabalha é igual a 15. Deste grupo que trabalha o principal motivo para tal tarefa é referente a questões pessoais, como "ter dinheiro para si próprio" (8), e "ajudar os pais" (6). Para a opção "outros" a justificativa apresentada foi referente e obter dinheiro para estabilidade fora do Brasil em planos futuros. Vale destacar que os meninos compunham a maior parcela de escolares que trabalham. Em concordância com esses resultados Bacil et al (2013) também identificou em sua pesquisa que $80 \%$ dos escolares não trabalham, dentre esse grupo a maior parte era composta por meninas.

Após todos os resultados apresentados e discutidos, notou-se que na grande maioria dos escolares prevaleceram respostas positivas quanto aos aspectos das aulas de $E F$, havendo convergências como foi apresentado. Mesmo que em alguns momentos o conceito de QV pareça deslocado, entende-se que é associado em maior parte das respostas, à prática de AF. A estrutura do colégio apresenta-se razoavelmente boa para as aulas de EF mesmo com os materiais convencionais.

Os aspectos negativos aparecem pouquíssimas vezes nas respostas dos escolares bem como nos sentimentos apresentados. Para todos os fins, as aulas de EF tem papel fundamental para mudança de comportamento em relação ao estilo de vida, uma vez que muito foi comentado sobre a prática de AF e QV nos aspectos das aulas e sendo assim, os níveis de AF destes escolares apresentaram-se razoavelmente significativos. Desta maneira, Dresch, et al. (2013) comenta sobre o papel do professor de EF:

os adolescentes parecem estar mais predispostos e atentos em relação ao sedentarismo e à AF. Em função disso, torna-se importante a implantação de programas de incentivo à prática de $\mathrm{AF}$ para eles, não apenas na busca de uma melhoria no estado de saúde atual, mas também na tentativa de prepará-los para a prática regular de AF na idade adulta. O papel do professor de EF nessa problemática é fundamental, devendo acompanhar os alunos, motivando-os mediante estratégias pedagógicas visando os interesses deles, fortalecendo o desenvolvimento de hábitos de vida saudáveis (DRESCH, et al. 2013, p. 369).

Sendo assim, cabe aos profissionais de EF a tarefa de orientar crianças, adolescentes, adultos e idosos a repensarem seus hábitos e comportamentos diários, sejam eles bons ou ruins. Afinal de contas, muitas vezes o que pode estar faltando é apenas um empurrãozinho para que se abram novos horizontes.

\section{Considerações Finais}

Mediante os achados da pesquisa em tela, conclui-se que os objetivos propostos no início do trabalho foram atingidos. Identificou-se que os escolares da instituição de ensino investigada apresentam números significativos para um nível de AF considerado "pouco ativo" e também "moderadamente ativo", e que dessa população os meninos apresentam-se mais ativos que as meninas.

A relação existente entre a qualidade e satisfação dos alunos com as aulas de EF e os níveis de AF apresentados, refutam a hipótese de que quanto mais positiva fosse a satisfação dos escolares com as aulas, maior seriam os níveis de AF fora da escola, tendo em vista que mesmo que pareça que os escolares estejam satisfeitos com suas aulas de EF, o nível de prática de AF fora do âmbito escolar apresenta escores baixos. Além disso, mesmo assumindo o gosto pela prática de AF, isso apresentou-se de maneira oposta comparado com os resultados apresentados. Portando, novos estudos nesse sentido podem contribuir com o estopim desta pesquisa. 
Além disso, notou-se que por mais que os conteúdos trabalhados pela disciplina favoreçam a adoção de um estilo de vida ativo, muitas esferas não correspondem aos anseios dos alunos. Diante disso aponta-se a importância da construção do ensinoaprendizagem tendo os interesses dos alunos levados em consideração. O professor é o principal responsável por mediar todo processo de ensino e oferecer-lhes as mais diferentes práticas, sejam elas esportivas ou outras atividades de caráter mais exploratório sobre a cultura corporal de movimento, visando erradicar ou minimizar a exclusão dos menos habilidosos.

No desfecho desta pesquisa apresenta-se novas possibilidades de estudos a respeito do tema $A F$ e saúde, tais como a realização de um estudo que indique se as aulas de EF melhoram os índices de AF fora da escola, e estudos longitudinais acerca da adoção de um estilo de vida ativo.

Entre as limitações do presente estudo estão o tamanho da amostra, sua característica predominantemente feminina, e a ausência de análise estatística. Sugeremse, para estudos futuros, novas investigações acerca da influência das aulas de EF nos níveis de atividade física de escolares e, em caráter longitudinal, de indivíduos adultos.

Por fim, com base no que foi exposto pela literatura, conclui-se que a EF na escola é um dos meios para a promoção de saúde, tendo em vista que ali se desenvolve e constrói o gosto pela prática da AF. Neste sentido, boas experiências tendem a ser levadas para a adolescência e a vida adulta.

\section{Referências}

AMERICAN COLLEGE OF SPORTS MEDICINE. Diretrizes do ACSM para os testes de esforço e sua prescrição. 9. ed. Rio de Janeiro: Guanabara, 2014, 268 p.

BACIL, E. D. A.; RECH, C. R.; HINO, A. A. F. Padrões de atividade física em escolares de Ponta Grossa, Paraná. Revista brasileira de atividade física e saúde, Pelotas, v. 18, n. 2, p. 177-185, mar. 2013.

BASSANI, J. J.; RICHTER, A. C.. Lesões, excessos e compulsões no âmbito das atividades físicas e esportivas (AFEs): conceitos, abordagens e reflexões. Relatório Nacional de Desenvolvimento Humando do Brasil. Disponível em: $<$ http://movimentoevida.org/wp-content/uploads/2017/09/Atividades-Fi\%CC\%81sicas-eEsportivas-e-Compulso\%CC\%83es-excessos-e-leso\%CC\%83es.pdf>. Acesso em: 17 nov. 2018.

BRANDOLIN, F. A percepção dos alunos sobre a educação física no ensino médio. Revista da Educação Física/UEM, Maringá, v. 26, n. 4, p. 601-610, out./dez. 2015.

BRASIL. Ministério da Educação. Base Nacional Comum Curricular: educação é a base - ensino médio. Disponível em: <http://basenacionalcomum.mec.gov.br/wpcontent/uploads/2018/04/BNCC EnsinoMedio embaixa site.pdf >. Acesso em: 17 nov. 2018.

Lei de Diretrizes e Bases da Educação Nacional. Brasil: Senado Federal, Coordenação de Edições Técnicas. 2017.

Lei $\mathrm{n}$ - 13.415, de 16 de fevereiro de 2017. Altera as Leis $\mathrm{n}$-9.394, de 20 de dezembro de 1996, que estabelece as diretrizes e bases da educação nacional, e 11.494, de 20 de junho 2007, que regulamenta o Fundo de Manutenção e Desenvolvimento da 
Educação Básica e de Valorização dos Profissionais da Educação, a Consolidação das Leis do Trabalho - CLT, aprovada pelo Decreto-Lei no 5.452, de 1ํ de maio de 1943, e o Decreto-Lei no 236, de 28 de fevereiro de 1967; revoga a Lei oㅜ 11.161, de 5 de agosto de 2005; e institui a Política de Fomento à Implementação de Escolas de Ensino Médio em Tempo Integral. Diário Oficial da União, Brasília, 17 de fevereiro de 2017. Disponível em: $<$ https://www.planalto.gov.br/ccivil 03/ ato2015-2018/2017/lei/l13415.htm>. Acesso em: 17 nov. 2018.

Brasil. Ministério da Educação e do Desporto. Parâmetros Curriculares Nacionais/ Ensino Médio: Linguagens, Códigos e suas Tecnologias. Secretaria da Educação Média e Tecnológica. Brasília. 2000.

VIGETEL. Ministério da Saúde. Secretaria de Vigilância em Saúde. Departamento de Vigilância de Doenças e Agravos não Transmissíveis e Promoção da Saúde. Vigilância de fatores de risco e proteção para doenças crônicas por inquérito telefônico: estimativas sobre frequência e distribuição sociodemográfica de fatores de risco e proteção para doenças crônicas nas capitais dos 26 estados brasileiros e no distrito federal em 2017. Brasília, 2018.

DRESCH, F. et al. Nível de atividade física de escolares da rede pública de ensino de um munícipio do Rio Grande do Sul. Revista Brasileira em Promoção da Saúde, Fortaleza, v. 26 , n. 3, p. $365-371$, jul./set. 2013.

FONSECA, V. Importância das emoções na aprendizagem: uma abordagem neuropsicopedagógica. Revista Psicopedagogia, Portugal, v. 33, n. 102, p. 365 - 384 , set./nov. 2016.

GIL, A. C. Como elaborar projetos de pesquisa. 4. ed. São Paulo: atlas, 2002. 176 p.

GOMES, R.; MINAYO, M. C. Atividade Física como parte importante da saúde em todas as idades. Ciência \& Saúde Coletiva, Rio de Janeiro, v. 21, n. 4, p. 1, abr. 2016.

GRECA, J. P. A.; SILVA, D. A. S.; LOCH, M. R. Atividade física e tempo de tela em jovens de uma cidade de médio porte do Sul do Brasil. Revista Paulista de Pediatria, São Paulo, v. 34, n. 3, p. 316-322, jun./nov. 2016.

GUEDES, D. P. et al. Níveis de prática de atividade física habitual em adolescentes. Revista Brasileira de Atividade Física e Saúde, Londrina, v. 7, n. 6, p. 187 - 199, 2001.

GUIMARÃES, A. A. et al. Educação Física Escolar: Atitudes e Valores. Motriz. São Paulo, v. 7, n. 1, p. 17-22, jan./jun. 2001.

LOPÉZ, A. R.; MAURA, V. G. Niveles de satisfacción por la classe de Educación Física. EFdeportes, Buenos Aires, v. 6, n. 32, mar. 2001. Disponível em: <http://www.efdeportes.com/efd32/satisf.htm>. Acesso em: 13 de nov. 2018.

MENDONÇA, G. et al. Padrões de prática de atividade física em adolescentes de um município da região Nordeste do Brasil. Revista Ciência e Saúde Coletiva, Paraíba, v. 23, n. 7, p. 2443-2451, 2018. 
NAHAS, M. V. Atividade física, saúde e qualidade de vida. 4. ed. Londrina: Midiograf, 2006. 282 p.

OLIVEIRA, E.; MORENO, A. C. Base Nacional Comum Curricular do ensino médio, BNCC, é aprovada pelo Conselho Nacional de Educação. Educação. Disponível em: $<$ https://g1.globo.com/educacao/noticia/2018/12/04/base-nacional-curricular-comum-eaprovada-pelo-conselho-nacional-de-educacao.ghtml >. Acesso em: 10 dez. 2018.

PAIVA, A. L. et al. Nível de Atividade Física em Adolescentes Saudáveis. Revista Brasileira de Medicina do Esporte, São Paulo, v. 22, n. 3, p. 191-194, mai./Jun. 2016.

PIMENTA, T. A. M. Tratamento multiprofissional: As limitações e potencialidades da intervenção na obesidade infantil. 2013. 131 f. Dissertação (Mestrado em Desenvolvimento Humano, Políticas Sociais e Formação) - Programa de Pós Graduação em Desenvolvimento Humano, Políticas Sociais e Formação, Universidade de Taubaté, Taubaté-SP.

SANCHES, T. M.; FERREIRA, A. O. O desinteresse dos alunos do ensino médio pelas aulas de educação física. Os desafios da escola pública paranaense na perspectiva do professor PDE, Secretaria de Estado do Paraná, vol. 1, 2014. p. 16.

SECRETARIA DE ESTADO DA EDUCAÇÃO DO PARANÁ. Diretrizes Curriculares da Educação Básica - Educação Física. Paraná, 2008. 90 p.

SILVA, A. A. P. Características do ambiente físico e organizacional para a prática de atividade física nas escolas de Curitiba, Brasil. Revista Brasileira de Atividade Física e Saúde, v. 23, n. 27, p. 1-10, 2018.

SILVEIRA, E. F.; SILVA, M. C. Conhecimento sobre atividade física dos estudantes de uma cidade do sul do Brasil. Revista Motriz, Rio Claro, v. 17, n. 3, p. 456-467, jul./set 2011.

TEIXEIRA, G. M.; GAGLIARDI, J. F. L.; ANDRADE, E. L. Nível de atividade física, o estilo de vida e o estágio de mudança de comportamento relacionado à atividade física. Revista Mackenzie de Educação Física e Esporte, São Paulo, v. 15, n. 1, p. 52-70, jan./jun. 2016. 